\title{
Escrita Pedagógica e Poder: Feiticeiras, Mediadoras e Literatura Vicentina
}

\author{
Pedagogical Writing and Power: Witches, Mediators and Vincentian \\ Literature
}

\begin{abstract}
Fernando de Sá Oliveira Júnior ${ }^{1}$
${ }^{1}$ Mestrando em História (UFAL); Orientadora: Profa. Dra. Raquel Parmegiani; pesquisador do Núcleo de Estudos e Pesquisas sobre Diversidade e Educação do Sertão Alagoano (NUDES/UFAL); pesquisador do Vivarium- Laboratório de Estudos da Antiguidade e do Medievo (UFAL); pesquisador do Laboratório de Pesquisas e Práticas de Ensino de História-LAPPEHis (UFAL). Tem como análise central pesquisas no campo cultural e religioso, versando sobre a representação literária ibérica da bruxa alcoviteira durante o século XVI. E-mail: fjunior.oli@hotmail.com.
\end{abstract}

Recebido em 26 de março de 2021; Aceito em 10 de julhol de 2021.

DOI: $10.12957 /$ nearco.2021.58662

\section{Resumo}

Buscamos analisar a escrita pedagógica e moralizante do Século XVI, através das obras escritas pelo Dramaturgo português Gil Vicente: "O velho da horta", "Auto da Barca do Inferno" e "Auto das Fadas". O autor se firmou como um dos maiores dramaturgos humanistas entre o final da Idade Média e início de Época Moderna. A literatura vicentina que caminha entre os Autos (gênero literário de teor moralizador e pedagógico) e as Farsas (literatura voltada para a comédia e a ironia), nos apresenta como figura central da sua obra, a figura da feiticeira alcoviteira. Este topoi feminino será aqui o fio condutor para que possamos conhecer mais o universo sociocultural da mulher nesta época e seu lugar no âmbito público e privado, visto que esta personagem dialoga com diversos grupos sociais.

Palavras-chave: História. Literatura pedagógica. Representações.

\begin{abstract}
We seek to analyze the pedagogical and moralizing writing of the 16th century, through the works written by the Portuguese playwright Gil Vicente: "O Velho da Horta", "Auto da Barca do Inferno" and "Auto das Fadas". The author established himself as one of the greatest humanist playwrights between the end of the Middle Ages and the beginning of the Modern Era. Vincentian literature that walks between Autos (a literary genre of moralizing and pedagogical content) and Farsas (literature focused on comedy and irony), presents us as the central figure of his work, the figure of the peach witch. This feminine topoi will be the guiding thread here so that we can learn more about the
\end{abstract}


sociocultural universe of women at this time and its place in the public and private spheres, since this character dialogues with different social groups.

Keywords: History. Pedagogical literature. Representations.

\section{Introdução}

Durante o final do século XV e início do XVI entre Portugal e onde hoje chamamos Espanha, o Tribunal do Santo Ofício multiplicava os seus tentáculos e outras forças, consolidando um aparelho repressor para além da Santa Inquisição. É neste contexto que a literatura secular e religiosa reproduzia o controle do comportamento social, seja através de tratados, literatura de espelhos ${ }^{170}$ e demais tipos que caracterizavam a literatura pedagógica.

Gil Vicente, autor que escreveu entre os anos de 1502 a 1536 - ano da sua morte e também da instauração da Inquisição em Portugal -, retratou através das suas farsas e autos inúmeros personagens- gêneros literários de teor moralizador, irônico e pedagógico- estabelecendo "tipos sociais" em um momento histórico marcado pela literatura pedagógica, com o intuito de imprimir o comportamento ideal da sociedade seiscentista, e assim a figura da feiticeira-alcoviteira é uma das personagens centrais das obras do dramaturgo humanista.

O modelo de mulher alcoviteira e que recorre a mediação das artes mágicas está presente em um vasto repertório literário, até mesmo anterior à Gil Vicente. Podemos encontrá-la em toda a literatura europeia da época, sendo esta figura um reflexo de algumas mulheres que realmente viverem naquele período, o que configura uma mistura entre literatura e realidade.

\footnotetext{
${ }^{170} \mathrm{~A}$ tradição dos espelhos surge no Medievo e prolifera sobretudo na França e em Portugal e Espanha ela ganha uma maior projeção entre os séculos XVI e XVII. A maior circulação desse material tinha um objetivo claro, por parte do poder político da época, orientar atitudes e comportamentos morais e religiosos. As narrativas literárias dos Espelhos eram direcionadas de maneira a "orientar" uma especificidade, por exemplo, os "Espelhos dos Casados". REIS, Marcus Vinicius. Mulheres de seus corpos e de suas crenças: relações de gênero, práticas mágico-religiosas e Inquisição no mundo português (1541-1595). Tese (doutorado)- Universidade Federal de Minas Gerais, Faculdade de Filosofia e Ciências Humanas. 2018. p.69-70.
} 
A presença da alcoviteira-feiticeira na literatura é anterior as mediadoras vicentinas e mesmo antes da alcoviteira hispânica Celestina de Fernando de Rojas (1499). Nelly Coelho (1963) destaca este topoi presente durante a comédia latina Pamphillus, ${ }^{171}$ contribuindo para a formulação literária da personagem, nesta obra aparece uma figura feminina, Doña Vênus, cuja função é facilitar a situação amorosa do protagonista Pamphillus, e esse se torna um topoi que se repetirá inúmeras vezes na literatura do século XV. No século XIV, a facilitadora amorosa ou alcoviteira entra mais uma vez de modo marcante para a literatura, por meio da obra de Juan Ruiz em El libro del Buen Amor (1939).

O personagem Arcipreste recorre a Trotaconventos, uma facilitadora, para ajudálo em seus amores com Doña Endrina. Nesta obra aparece uma certa precisam aquilo o personagem que será chamado de alcoviteira. Esta aparece como alguém que faz parte da intimidade das donzelas por desenvolver atividades que as auxiliam, como vender adornos e por isso podem fazer o papel de intermediadoras entre os homens e suas amadas.

Podemos dizer que o arcabouço psicológico da alcoviteira se configurou de fato com essa personagem Trotaconventos em todos os seus aspectos fundamentais, mais a personagem Celestina de Fernando Rojas, ${ }^{172}$ foi quem definira as linhas básicas da personalidade e da atuação da alcoviteira dentro da literatura.

Gil Vicente, com toda certeza inspirou-se em Doña Vênus, Trotaconventos e Celestina, para criar seus personagens, porém ele acrescenta características de figuras literárias da antiguidade à sua obra e em personagens reais contemporâneas de seu momento histórico.

\footnotetext{
${ }^{171}$ Obra erótica de autor desconhecido, divulgada no século XII.
}

172 Durante a obra Rojaniana publicada pela primeira vez em Burgos no ano de 1499 sob o título de Comedia de Calisto y Melibea, Celestina a alcoviteira-bruxa veio dar maior desenvoltura ao tipo, colocada como o foi dentro da unidade de uma intensa ação dramática: a atração amorosa entre Calisto e Melibea. Firmaram-se, assim, definitivamente os contornos dessa singular personalidade que é a alcoviteira: mulher madura, experimentada, dona de uma astuta sabedoria prática, conhecedora profundidade todos os desvãos das paixões humanas e convicta de que, no fundo, são estas que regem a vida. COELHO, 1963, p. 84. 
Maria José Palla $(1995$, p. 6) discute de como por volta do século Il antes da nossa era, a literatura grega através dos poetas latinos criava temas mágicos e personagens místicas, citando Medéia de Eurípides, ${ }^{173}$ personagem destacada entre as transposições mais famosas, as versões de Eurípides (séc. V a.C.), Sêneca (séc. I), Corneille (séc. XVII) e Jean Anouilh (séc. XX), sinalizamos ainda uma característica da obra a referência da situação da mulher nas diversas pólis gregas, Eurípides destaca algumas variações em relação aos aspectos femininos, contudo o signo da dominação era uma constante.

Diante dessas informações, propomo-nos a analisar a representação literária da bruxa alcoviteira na obra de Gil Vicente. Utilizaremos para este trabalho as personagens: Branca Gil, Brízida Vaz e Genebra Pereira. Todas elas estão envolvidas em atividades muito semelhantes que nos remete ao topoi da alcoviteira. Configuram assim uma mesma estrutura interna, herdada de personagens como Trotaconventos e Celestina; partilham a mesma função dentro da história, de mediar situações amorosa e têm a mesma condição social.

\section{A Inquisição portuguesa e a caça às bruxas}

Como o documento em latim mais antigo a se referir às superstições populares, o manuscrito de $1385^{174}$ que se encontra em Portugal, atribuído a uma autoridade civil, tendo em vista que a posteriori temos conhecimento de um esboço de inquisição a partir do século XIV, que julgava e condenava hereges, a que se seguiram as Ordenações Manuelinas.

Através do primeiro Monitório da Inquisição em Portugal, tendo sido publicado em 1536 que previa a competência jurisdicional da Inquisição estenderia seus "tentáculos" sobre os crimes de protestantismo, judaísmo, islamismo, blasfêmias, bigamias e a feitiçaria foi assimilada pela instituição no decorrer do século XV. Sendo

\footnotetext{
${ }^{173} \mathrm{~A}$ tragédia Medéia de Eurípides (480 - 406 a.C.), a exemplo dos demais textos que compõem o sistema literário da Antiguidade Clássica, fundamenta-se na tradição lendária e para além da feitiçaria que acompanha o mito de Medéia, existe uma reflexão sobre a condição de mulher, aviltada depois de sacrificar tudo em nome de uma paixão. DUTRA, Enio Moraes. O mito de Medéia em Eurípides. Revista Letras; n. 1. Universidade Federal de Santa Maria. 1991.
}

${ }^{174}$ Livro 2- de El- Rei D. João I, fl. 16 et ss. Arquivo da Câmara Municipal de Lisboa. 
assim, a ação inquisitorial no mundo português segue por um caminho a vigiar as consciências dos indivíduos, ampliando as concepções de vigilância até as práticas religiosas de cada um.

A ação inquisitorial persegue ainda indivíduos praticantes do crime de feitiçaria, em destaque e maior número as mulheres, sendo acusadas de tal crime foram perseguidas e castigadas durante toda a Idade Média, contudo é durante a Época Moderna que elas passam a ser executadas pelos Autos de Fé. 175

A literatura foi constantemente utilizada para condenar práticas que era definidas como bruxaria. Destacamos aqui o impresso português, o Tratado de Confissom, ${ }^{176}$ nele consta os questionamentos que devem ser feitos às acusadas e acusados quando estes fazem feitiços, encantamentos e adivinhações.

Evidenciando de como era vista tal temática, destacamos alguns léxicos para se referir quanto a temática; no mundo português existem "feitiçaria" e "bruxaria", em Espanha Maria José Palla apresenta as palavras "hechiceria" e "brujeria", equivalentes respectivamente as expressões de Portugal. A língua inglesa contém os termos "witch", "witchcraft" e "sorcer"; a língua francesa unicamente a palavra "sorcière" e a língua italiana as palavras "stregoneria" e "fattucchiria", estas identificadas como equivalentes ao aos léxicos ingleses. (PALLA, 1995, p. 300).

Em relação a demais léxicos, Maria Palla destaca haver uma complexidade na tradução e significação desses termos, explicitando que a temática já discutida na historiografia por Francisco Bethencourt (2004) e Laura de Mello e Souza (1987). Em algumas significações a bruxa aparece com uma mulher idosa, que mantém relações com o Demônio e suas habilidades são herdadas desde o nascimento; a feiticeira é, muitas vezes, retratada como uma mulher jovem, que aprende a manipulação das artes mágicas a posteriori através de rituais e encontros coletivos.

\footnotetext{
${ }^{175}$ Os autos-de-fé consistiam em cerimônias mais ou menos públicas onde eram lidas e executadas as sentenças do Tribunal do Santo Ofício (instituição criada pela Inquisição no século XVI). Com o passar do tempo, os autos-de-fé passaram a constituir um grandioso espetáculo, realizado com grande pompa e segundo um cerimonial rigorosamente estabelecido. Assistiam a estas cerimônias não apenas as autoridades religiosas e civis (muitas vezes o próprio rei estava presente), mas toda a população da cidade que gritava em júbilo enquanto os condenados eram queimados vivos. Dicionário de História.
}

${ }^{176}$ Tratado de Confissom, Chaves, 1489, edição de José V. de Pina Martin. 
Quanto a atuação do Tribunal do Santo Ofício em Portugal, o historiador Antônio Manuel Hespanha (2012) ressalta que haja uma forte conotação religiosa a respeito do Direito português. Destacamos ainda nesta questão as Ordenações Manuelinas, conforme Marcus Vinícius Reis (2018) aponta como um relevante conjunto jurídico que possibilitou constatar as concepções de feminilidade e masculinidade, tendo sido gestadas aos discursos jurídicos que pretendiam regulamentar, papéis sociais determinados aos homens e às mulheres durante o século XVI, o autor enfatiza ainda a repercussão do conjunto jurídico:

(...) o interesse das autoridades portuguesas em estender a vigência desse código jurídico por toda a vida social dos súditos, além de versar sobre os crimes passíveis de punição, tais como a feitiçaria e a bruxaria. Já as Chancelarias Régias, mecanismos utilizados largamente pela monarquia lusitana ao longo dos séculos $\mathrm{XI}$ a XV, são citadas a fim de analisar como a Coroa tratou o delito da feitiçaria e qual a sua relação com a figura das mulheres, antes mesmo do estabelecimento da Inquisição em 1536 (REIS, 2018, p. 49).

Sendo assim, a literatura jurídica produzida durante o final da Idade Média e início da Época Moderna auxiliou a definição dos papéis referentes a homens e mulheres, reforçando a propagação de princípios hierárquicos e excludentes em relação as mulheres e a escrita como instrumento de poder. É possível perceber nessas leis a sustentação da ideia do homem como um ser perfeito e reprimindo quaisquer comportamentos dissonantes daqueles estabelecidos pela Igreja Católica; nessas mesmas leis a mulher ganha um lugar nada privilegiado, muita das práticas do cotidiano feminino aparece numa estreita relação com a feitiçaria.

Pode-se dizer que as acusações de bruxaria que recaí sobre muitas ações e comportamentos das mulheres funcionam, muitas vezes, como forma de manter uma condição normativa que as inferioriza e as submete à continuidade da ordem social vigente.

Isto aparece, inclusive, na forma como a medicina propõe a hierarquia entre gênero masculino e feminino no século XVI. Segue-se, sem dúvida a lógica de contrariedade e interdependência, o modo de "ser homem" e "ser mulher", estabelecia 
o que a mulher deveria ser com base no homem, prevalecendo o discernimento de que a honra ideal a ser deferida elas mulheres seria a submissão ao homem.

Desde Galeno e Aristóteles, entendia-se que homem e mulher eram iguais, diferenciando-se na estrutura reprodutiva feminina, a qual correspondia ao oposto da masculina. O modelo do sexo único, paradigma assentado por Thomas Laqueur, ${ }^{177}$ elaborado durante os séculos XVI a XVIII e perdurou até o período em "que as refutações a esse modelo ganharam maior força no contexto iluminista" (REIS, 2018, p. 51).

Desse modo, os teóricos que manifestavam entusiasmo em relação as discussões acerca do corpo humano enfatizavam prontamente a feminilidade como um padrão atribuído a inferioridade e opostos a referência masculina estabelecida no período destacado, para tanto é necessário entender a relação entre textos jurídicos e literários, Marcus Reis destaca ainda:

\begin{abstract}
Cabe ao pesquisador, segundo a Butler, avaliar "que tipo de repetição subversiva poderia questionar a própria prática reguladora da identidade?" Questiona-se, nessa tese, se ao construírem suas famas e autonomias a partir do delito da feitiçaria, as mulheres feiticeiras se tornaram exemplos dessa "repetição subversiva", sendo capazes de romper com a heterossexualidade compulsória. A resposta para essa questão começa com a análise a respeito de quais padrões hegemônicos, baseados nessa heterossexualidade compulsória, foram construídos no mundo português, a começar pelo universo jurídico e secular (REIS, 2018, p. 52).
\end{abstract}

\footnotetext{
${ }^{177}$ Thomas Walter Laqueur é um historiador, sexólogo e escritor americano. A tese de Laqueur é reafirmada pelo trabalho de L. Schiebinger (1987). Ao estudar a descoberta das especificidades do esqueleto feminino, fornece um exemplo bastante interessante de como a anatomia é moldada por circunstâncias sociais. Segundo essa autora, é no contexto da tentativa de redefinição da posição da mulher na sociedade europeia do século XVIII que surgem as primeiras representações do esqueleto feminino, provando que os interesses da ciência não são arbitrários, mas que focam partes do corpo politicamente significantes. É o caso da afirmação de que a mulher tem um crânio menor, consequentemente menos capacidade intelectual e, portanto, menos condições de participar dos domínios do governo, comércio, educação, ciência. Ou, então, da constatação de que ela tem a pelve maior, o que prova que é naturalmente destinada à maternidade. Durante os séculos XVIII e XIX, a ciência cada vez mais evidencia que a natureza humana não é uniforme, mas se diferencia de acordo com idade, raça e sexo. Assim como Laqueur, Schiebinger também conclui que não é apenas uma questão de desenvolvimento científico. Pois, a anatomia já dissecava corpos de mulheres, o que poderia levar à observação das diferenças, mas isso não acontecia. Os anatomistas explicavam as diferenças que percebiam como meramente externas, sem grande importância porque não chegavam às estruturas mais profundas. ROHDEN, Fabiola. O corpo fazendo a diferença. Ensaio Bibliográfico. Mana, vol.4 n.2 Rio de Janeiro. 1998.
} 
Posto isto, constatamos a influência arrebatadora dos juristas na constituição de uma literatura e documentação legal, forjando uma anuência de que a essência masculina deveria abarcar o feminino, subordinando as mulheres, já que conforme Hespanha elas eram caracterizadas como a cabeça, e assim "[evocava], naturalmente, todo o corpo" (HESPANHA, 2010, p. 103); apontando o homem então, como um ser pensante e dotado de sabedoria capaz de direcionar a mulher. Para os juristas a predisposição feminina a submissão às forças malignas era uma prova dessa superioridade masculina, sendo a religião e a heterossexualidade compulsória o "carrochefe" da perseguição às mulheres acusadas de praticar bruxaria.

Evidenciando a eficácia da ação do tribunal português em Rossio de Lisboa durante a regência de D. Catarina ${ }^{178}$ em 1559, foram queimadas cinco mulheres acusadas de práticas de bruxaria. De acordo com a autora, durante a documentação as mulheres acusadas de realizar pacto com o diabo se tornariam uma "bruxa", a figura de um bode é constantemente associada ao demônio, e aquela (e) que deseja ser fiel ao Senhor das Trevas deve renegar seu batismo cristão, escrever o nome no livro negro e celebrar juntamente com o coletivo que também ali estava ofertando-se as forças malignas em troca de favores e mediações de todo o tipo.

Maria Pallanca assim como Carlo Ginzburg, ao analisar as descrições que os documentos nos deixaram sobre as reuniões noturnas, nas quais as bruxas com sangue de criança banhado ao corpo permitiam o milagre do voar, ocasionando assim as assembleias em lugares como Val de Cavalinhos, destacado elo autor português Gil Vicente, mantendo uma espécie de relação sexual, adoração e partilhas de segredos entre si.

\section{Idiossincrasias psicológicas da Feiticeira Alcoviteira Vicentina}

Na galeria de feiticeiras-alcoviteiras do escritor Gil Vicente, entre as três que escolhemos analisar, a que mais evidencia a complexa e dinâmica referente às características e performance psicológica deste topoi é Branca Gil de "O velho da Horta",

\footnotetext{
${ }^{178}$ Catarina de Bragança.
} 
farsa ${ }^{179}$ de 1512 e representada ao Rei Dom Manuel. Branca Gil conforme Nelly Novaes Coelho (1963) sublinha, que embora seja uma das mais completas, tenha sido a segunda criada cronologicamente falando por Gil Vicente.

A personagem Genebra Pereira de "Auto das Fadas" 180 foi a primeira a ser criada, embora a data correta de criação da peça seja desconhecida. Brízida Vaz a terceira feiticeira e alcoviteira aparece em "Auto da Barca do Inferno", representada em 1517, a peça encena uma prática ligada a bruxaria, com pena prevista nas Ordenações Manuelinas. Embora a feitiçaria durante a peça neste caso é realizada no paço e durante a presença do rei e sua corte, neste caso a insurgência é causa de um sentido, apesar de tal justificativa não livrar a obra de uma futura censura.

O êxito durante as peças vicentinas de personagens como Genebra Pereira, está nos atributos de esperteza das ações e mediações, e não necessariamente nos sortilégios e unguentos, conforme observamos no decorrer das falas da alcoviteira. ${ }^{181}$

Destacamos enfaticamente o quanto em Genebra Pereira, Gil Vicente retrata bem o uso dos bruxedos que dominou o Medievo. A feitiçaria, o pacto com o demônio, os filtros e unguentos eram os meios de que se utilizavam normalmente as "mediadoras do amor", percebe-se ainda como esta alcoviteira justifica com maestria a utilidade de seus serviços: "Assi que as taes feitiçarias são, Senhor, obras mui pias e não ha mais na verdade. Saiba Vossa Magestade quem he Genebra Pereira, que sempre quis ser solteira, por mais estado de graça" (VICENTE, 1944, p 184).

O enredo que envolve a personagem Genebra Pereira na passagem acima põe as ações e práticas das alcoviteiras, sob a suspeita do pecado, fica claro na cena que elas

\footnotetext{
${ }^{179}$ As Farsas são peças de um só ato com um enredo e número de personagens reduzidos. Busca retratar o cotidiano de forma cômica.

180 O texto do Auto das Fadas está inserido na Compilação sem indicação de data nem de local de representação. No entanto, o texto fornece dados para a sua contextualização. Terá por isso sido escrito em Lisboa no reinado de D. Manuel I, pois o texto refere-se ao príncipe e as infantas (D. João, D. Isabel e D. Beatriz respectivamente). Uma das personagens, o Frade adianta ainda no seu sermão a convertere ad dominum, exclamação típica da Semana Santa. A farsa foi censurada pelo Index de 1551, não porque punha ao ridículo as pessoas da Corte, mas porque se representava a bruxaria e a heresia. MATEUS, Osório (Dir.). Cadernos Vicente: Fadas. Quimera. Lisboa. 2005.

181 “Por feitiços que eu faço dizem que sou feiticeira. Porém Genebra Pereira nunca fez mal a ninguém, mas antes por querer bem ando nas encruzilhadas às horas que as bem-fadadas dormem sono repousado" (VICENTE, 1944).
} 
não eram regidas pela benevolência, mas sim pela ambição; este é o sentimento que governaria os feitos dessas mulheres, muito embora elas salientem estar agindo em prol do casal de amante.

Auto das Fadas é dividida em duas partes, a primeira constituída por uma consulta de feitiçaria e pelo discurso de um monge, e na segunda parte, a corte participa num jogo de enigmas e estabelecem-se comparações entre animais e cortesãos.

No decorrer da obra, Genebra Pereira apresenta-se, informa que tem quarenta anos, sua origem nobre, e que, tal como muitas alcoviteiras do teatro humanista francês do século XVI, possui uma educação na corte; relata ainda a sua castidade, segundo a alcoviteira, tal reclusa lhe proporciona maior desenvoltura junto as artes mágicoreligiosas, justifica ainda a motivação de realizar as magias e alcovitices, reforça que ao ser requisitada pelos enamorados que padecem de amor, seria desumana ao não atender tais súplicas.

Basicamente em "Auto das Fadas", trata-se da teatralização de um ato socialevidenciando a originalidade de Gil Vicente- em que retrata a corte assisti a uma sessão de feitiçaria. Fica subentendo a possibilidade de perdão aos atos da alcoviteira, caso fosse provado que tais artes não atentavam contra as leis de Deus. A feiticeira fala de suas viagens e voos noturnos e estando despida quando os realiza, indo em favor daqueles que sofrem no amor, tendo por adorno somente um talismã antigo no pescoço, o "Sino Salmão". ${ }^{182}$

Em 1512 Gil Vicente cria Branca Gil, influenciado pela Celestina de Fernando de Rojas. Além das características comuns a todas às alcoviteiras, constata-se que esta não seduz e persuadi os enamorados, ela é solicitada de maneira fervorosa. A trama se desenvolve em um jardim, destacamos que a alcoviteira já havia sido punida anteriormente pelas suas práticas; serve de mediadora um velho, tendo sido solicitada para a mediação enquanto compra verduras, sendo convencida a livrar aquele homem de uma dor terrível: a ânsia da paixão.

\footnotetext{
182 O "sino salmão" ou Selo-de-Salomão, composto por dois triângulos entrelaçados, objeto profiláctico continha o mau olhado. Colocara este amuleto no interior de um coração de gato negro, função simbólica redundante, pois estamos em presença de duas figuras simbólicas sobrepostas.
} 
A alcoviteira é uma mulher atribuída a sagacidade, uma sabedoria prática que está em torno das reflexões de temas como a justiça, as relações entre os homens, as paixões terrenas e demais assuntos ligados a sociedade. Branca Gil diante das declarações do velho relatando estar apaixonado, mostra-se compreensiva e lhe diz as palavras que deseja ouvir, ${ }^{183}$ justificando como um sentimento ideal através da experiência do homem maduro; percebemos assim o conhecimento que ela detém acerca dos sentimentos do homem (COELHO, 1963, p. 9)

Para além das expertises, uma alcoviteira eficaz também recorria as artes mágicas, embora durante as obras de Gil Vicente, o dramaturgo evidencia que o sucesso das mediações é proveniente também da astúcia e sabedoria dessas mulheres. Através da personagem Genebra Pereira, mencionada já aqui, Gil Vicente evidencia além da astúcia, sublinha a utilização constante das magias, práticas que dominaram a Idade Média, bem como a feitiçaria, o pacto com o demônio, os filtros e unguentos, geralmente utilizados para o amor.

Durante a trama, Branca Gil reproduz apreço pelo velho, instigando e confortando-o em relação a sua capacidade de sedução e viver o amor. A alcoviteira carrega uma "cestinha", atribuída ao que poderia ser o caldeirão, e seus calçados estão gastos, uma das marcas de sua profissão, contudo com o intuito de melhorar sua figura, pede dinheiro para comprar roupas novas. Por fim, ao dizimar o velho, Branca Gil é condenada, sendo possivelmente levada a fogueira para assim purgar as suas culpas (PALLA, 1995, p. 308).

Em Auto da Barca do Inferno de 1517, temos a alcoviteira-feiticeira Brízida Vaz, que assim como outros personagens que representam os tipos sociais ${ }^{184}$ que aparece, no na história, estão mortos e iniciam a busca pelas barcas que irão tomar no contexto post-mortem. Além dos tipos sociais, a obra contém os personagens alegóricos, ${ }^{185}{ }^{10 m o}$ um frade, um fidalgo, um judeu, um sapateiro, e um parvo.

\footnotetext{
${ }^{183} \mathrm{Em}$ relação ao amor que o velho sentia ela moça mais jovem.

${ }^{184}$ São personagens que representam os tipos terrenos, por exemplo, o comerciante, o sapateiro etc.

${ }^{185}$ São os personagens que representam os sentimentos abstratos e sensações, por exemplo, Deus, o Diabo, anjos etc.
} 
Brízida Vaz ao chegar no mundo para além vida, leva consigo entre outras coisas "três arcas de feitiços e seiscentos virgos ${ }^{186}$ postiços". ${ }^{187}$ Isto lhe permite restaurar a virgindade das mulheres; arranjar amantes para homens eclesiásticos; e praticando abortos. Assim como Branca Gil, também Brízida Vaz se queixa constantemente de seus sapatos gastos, associando a sua profissão e o fato de andar de um lugar a outro.

Em relação as alcoviteiras-feiticeiras analisadas, evidenciamos ainda a origem dos nomes de algumas das personagens, que são provenientes de etimologia judaica e celta; sendo a última derivada do Ciclo do Rei Artur. Durante a Idade Média, era comum histórias de aventuras e cavalaria, propagadas pelos trovadores e que a posteriori foram passadas à prosa, sendo muito admirada pela sagacidade moral e religiosa.

A genuína feiticeira Genebra Pereira, a mesma que vai ao sabat e possui uma descendência nobre e proveniente de Guenièvre, a esposa do rei Artur, a que engana Lancelot e que será queimada, entretanto acaba por ser salva por ele. Genebra Pereira tem um duplo nome diabólico: Genebra e associado a Guenièvre, "a mulher má", e Pereira de "pêra". A palavra "pêra" vem do latim popular pira, que deriva do latim clássico pirum, que, por consonância, evoca o pior (PALLA, 1995, p. 311).

Quanto a etimologia do nome Branca Gil, é atribuído ao tom de pele pálido e branco, o branco da luz, o da Virgem Maria, uma luz próxima a luminosidade. 0 sobrenome ou apelido Gil lembra Gillot, expressão ligada também ao branco, evocando a ideia de a magia da alcoviteira ser branca (do bem), tendo em vista que a mesma não conjura com o auxílio do demônio. No imaginário em Portugal as feiticeiras se vestem de branco assim como as fadas, cor aliás que contrasta com o negro, ao qual estão as trevas e associado ainda aos corvos, gatos negros e o próprio diabo, evidenciando o quanto as simbologias e etimologias são importantes a fim de entender os meandros da literatura humanista.

\footnotetext{
186 Himens postiços.

${ }^{187} \mathrm{Gil}$ Vicente destaca ainda que a alcoviteira leva três armários de mentir, e cinco cofres de enleio, e alguns furtos alheios. VICENTE, Gil. Autos e farsas de Gil Vicente. São Paulo: Editora Melhoramentos, 2012.
} 


\section{Entre Autos, farsas e o posicionamento do Autor}

Nos cabe aqui questionar as representações e ironias que estão por trás destes três personagens de Gil Vicente, sejam eles religiosos ou seculares. A intenção por trás de cada um dos personagens, evoca sempre um caráter pedagógico, característica aliás norteadora dos seus trabalhos. O teatro vicentino evidencia o que se considera nocivo aquela sociedade, o mal e de como aqueles que o praticavam seriam castigados.

O autor, de forma geral, executa um trabalho de equilíbrio; pois alimenta em suas personagens e no contexto pequenas intrigas, insere o cômico, o burlesco e o grotesco todos no discurso e costurando em suas representações, discutindo ainda virtudes, vícios e a sociedade de sua época.

Para além do aspecto de verdugo, ${ }^{188}$ Maria José Palla aponta que na obra de Gil Vicente, o castigo não é o único desfecho para o topoi da alcoviteira, visto que este autor traz certa tolerância para com tipo social feminino. Em $O$ auto das fadas, Genebra Pereira censura um frade trapaceiro que oferece lhe prestar auxílio:

Olhade a gente honrada. Que me trazia o ladrão! Hum que foi amancebado, alcoviteiro provado, e hum frade rafião. Sabeis quão mal me parecem pessoas de mao viver? Mais cá moscas m'aborrecem, não nas posso ouvir nem ver (VICENTE, 2012, p. 200).

Obviamente tal maneira de abordar a alcoviteira não deve ser caracterizada como uma intenção do autor em desprezar esse tipo social, evidencia uma atitude de profunda compreensão da sua "razão de existir", em meio aquele organismo social, revelando ainda a crença de que nenhuma lei poderia extinguir a alcoviteira.

Constatamos o quanto Gil Vicente utiliza a alcoviteira ${ }^{189}$ para criticar o indecoro de um membro do clero, aliás uma das classes mais influentes daquela época. Fica claro o uso que o autor faz das várias Ordenações Afonsinas e Manuelinas para construir

188 Indivíduo responsável pela execução da pena de morte ou de outros castigos corporais; carrasco, algoz.

${ }^{189}$ A função da alcoviteira neste caso nos parece não só social/realidade, mas também literária. Ela parece ser o pivô que possibilita o autor criticar os personagens clericais. 
dentro das cenas, as ações dos clérigos. Observamos então que a alcoviteira, é um tipo social que tem dentro da obra de Gil Vicente, a função de criar cenas que possibilite que personagens socias de sejam escrachados, abrindo-se sobre eles um lugar à crítica social e moral.

Essa era necessária ser escrachado ao público, o que Gil Vicente articula a escrita como instrumento de poder, criticando através de um tipo social que de modo algum estaria habilitada a realizá-la: a alcoviteira (COELHO, 1963, p. 15).

\section{Considerações Finais}

Gil Vicente foi o primeiro autor português a introduzir bruxas e feiticeiras na literatura. A representação que ele forja corresponde a literatura encontrada em toda a Europa e ligada ao Carnaval e a um universo invertido; a alcoviteira vicentina lida com clérigos, nobres e plebeus, cumprindo um dever a sociedade de servir as paixões daqueles que a procuram (PALLA, 1995, p. 16).

O autor utiliza a escrita como um instrumento de poder pedagógico, ${ }^{190}$ igualando o homem a mulher no que diz respeito aos amores físicos dos clérigos, evidenciando intencionalmente através da superioridade moral da alcoviteira, pois se ela fosse condenada, toda a sociedade seria.

Notamos ainda o quanto Gil Vicente constrói uma representação multifacetada da alcoviteira, inspirada numa personagem que teria vivido realmente em Lisboa nessa época, o que nos pode sugerir que tenha seguido a mesma linha nos demais personagens (PALLA, 1995, p. 16).

Embora as alcoviteiras justifiquem sua atuação como relevante para sanar as questões amorosas, o preço para que tais serviços fossem executados era em geral muito alto. O provento cobrado pelas alcoviteiras era aliás, um dos defeitos mais citados

\footnotetext{
${ }^{190}$ Chamado por alguns de uma Moral utilitarista.
} 
pelos "beneficiados", tendo em vista a ambição no que se pedia ou no quanto pedia; a impressão inicial é de que essas mulheres exploravam a boa-fé daqueles que recorriam a mediação, entretanto, através de uma análise mais apurada, concluímos que tal particularidade completa, de maneira coerente como um sinal de negociação, discutindo as orientações acerca do que está sendo solicitado e ao final apenas o preço é combinado.

A alcoviteira em Gil Vicente não se trata apenas das velhas ex-prostitutas que desencaminham moças, ${ }^{191}$ mas sim de mulheres que utilizam sua sabedoria para a subsistência. Por fim, os séculos passam, os espaços geográficos são distintos, embora tudo se modifique, a permanência de homens ou mulheres que recorrem a outrem para mediar o amor e os desejos do corpo, tal elemento permanece obstante as interferências religiosas e seculares, sejam alcoviteiras, bruxas, feiticeiras ou outras designações, tal ofício prossegue "costurado" a ordem social.

\section{Referências}

\section{Documentação}

VICENTE, Gil. Autos e farsas de Gil Vicente. São Paulo: Editora Melhoramentos, 2012. . Obras Completes, vol. V, Livraria Si da Costa Editora, Lisboa, 1944.

\section{Bibliografia}

BETHENCOURT, Francisco. O imaginário da Magia: feiticeiras, adivinhos e curandeiros em Portugal no século XVI. Companhia das letras, 2004.

COELHO, Nelly Novaes. As alcoviteiras Vicentinas. Alfa. Revista de Linguística. Vol. 4. 1963.

${ }^{191}$ Como ocorre em La Celestina de Fernando de Rojas em Espanha. 
DUTRA, Enio Moraes. O mito de Medéia em Eurípides. Revista Letras. Universidade Federal de Santa Maria. Rio Grande do Sul, v.1, n. 1., 1-9, 1991.

HESPANHA, António Manuel. Imbecilitas: as bem-aventuranças da inferioridade nas sociedades do Antigo Regime. São Paulo: Anablume, 2010.

. Caleidoscópio do Antigo Regime. São Paulo: Alameda, 2012.

MATEUS, Osório (Dir.). Cadernos Vicente: Fadas. Quimera. Lisboa. 2005.

MELLO E SOUZA, Laura. A feitiçaria na Europa Moderna. Editora Ática, 1987.

PALLA, Maria José. Figuras literárias de magas e imagens de Sabat na obra de Gil Vicente. Revista da Faculdade de Ciências Sociais e Humanas. Lisboa, Vol.2; n.8, 297-312. Universidade Nova de Lisboa. 1995.

PROSPERI, Adriano. Tribunais da Consciência: Inquisidores, Confessores, Missionários. Trad. de Homero Freitas de Andrade. São Paulo: Editora da Universidade de São Paulo, 2013.

REIS, Marcus Vinicius. Mulheres de seus corpos e de suas crenças: relações de gênero, práticas mágico-religiosas e Inquisição no mundo português (1541-1595). 2018. 367 fls. Tese de Doutoramento: Universidade Federal de Minas Gerais. Programa de Pósgraduação em História. Faculdade de Filosofia e Ciências Humanas. Belo Horizonte, 18 de dezembro de 2018.

ROHDEN, Fabiola. O corpo fazendo a diferença. Ensaio Bibliográfico. Mana, vol.4 n.2 Rio de Janeiro. 1998.

RUIZ, Juan. El Libro del Buen Amor. Editor M. Alfredo Angulo, Buenos Aires, 1939.

VICENTE, Gil. Autos e farsas de Gil Vicente. São Paulo: Editora Melhoramentos, 2012. 